\title{
An incidental finding of congenital methaemoglobinaemia in a patient with an allergy
}

\author{
K G A Kumara ${ }^{1}$, S Suganthan ${ }^{2}$, T Kumanan ${ }^{2}$ \\ Ceylon Medical Journal 2013; 58: 91-92
}

\section{Case report}

A 23-year old unmarried woman who had been apparently well until three days prior to admission had developed urticarial rash, cough and difficulty in breathing after eating beef. On admission, she was comfortable at rest, not pale, and had central cyanosis. There was no finger clubbing or ankle oedema. She was haemodynamically stable, heart sounds were normal and there were no murmurs. Respiratory system examination was unremarkable except for occasional ronchi on auscultation. Her oxygen saturation on room air was $85 \%$ and it did not improve with additional oxygen supplementation via face mask.

She had a good clinical recovery from the allergic reaction to beef and became asymptomatic in two days. However the central cyanosis was persistent and her oxygen saturation on room air was persistently low and remained around $85 \%$ despite clear lung fields. This warranted further evaluation.

ECG, chest radiograph and other initial blood investigations including full blood count and ESR were normal. Blood gas analysis was performed while her saturation was $85 \%$ on room air. It showed, $\mathrm{pH} 7.46, \mathrm{pCO}_{2}$ $36 \mathrm{mmHg}, \mathrm{pO}_{2} 97 \mathrm{mmHg}, \mathrm{SpO}_{2} 97 \%, \mathrm{HCO}_{3} 25 \mathrm{mmHg}$. The $2 \mathrm{D}$ echocardiogram and contrast echocardio-gram with agitated saline were normal and this excluded intracardiac and pulmonary A-V shunts.

She was the third child of a consanguineous marriage. Her sister and brother who were asymptomatic had saturations of $88 \%$ and $92 \%$ respectively on pulse oximetry. Photospectrometry for methaemoglobin was positive. Haemoglobin electrophoresis excluded haemoglobin M disease. A diagnosis of congenital methaemoglobinaemia was made based on clinical and laboratory evaluation. She was counselled about the importance of avoiding certain medications and substances.

\section{Discussion}

Methaemoglobin is the oxidised form of haemoglobin and it can be formed due to congenital enzymatic defects, alterations in the hemoglobin molecule, or as a result of medications or toxins. Co-oximetry is the gold standard for diagnosis.

Congenital methaemoglobinaemia due to NADHcytochrome b5 reductase 3 deficiency is an autosomal recessive disorder. It present as two distinct phenotypes, type I and type II. In type I, the enzyme deficiency is restricted to erythrocytes and associated with benign cyanosis while the less common type II is associated with generalised enzyme deficiency affecting all cells and is lethal in early infancy [2].

The $\mathrm{SpO}_{2}$, when measured in arterial blood gas analysis, is calculated from blood $\mathrm{pH}$, the $\mathrm{SpO}_{2}$ and the standard haemoglobin dissociation curve. Methaemoglobin can falsely elevate the calculated $\mathrm{SpO}_{2}$. $\mathrm{CO}$ oximeter measures light absorbance at four different wavelengths that correspond to the absorbance characteristics of deoxy-haemoglobin, oxy-hemoglobin, carboxy-hemoglobin and methaemoglobin. Therefore $\mathrm{CO}$ oximeter can distinguish between these and can give a more accurate measurement of $\mathrm{SpO}_{2}$ [3]. The difference between the calculated oxygen saturation from a standard blood gas machine and the reading from the pulse oximeter is the "saturation gap". If it is more than $5 \%$, it may be due to carbon monoxide poisoning, methaemoglobinaemia or sulfhaemoglobinaemia [4].

Symptoms correlate with the level of methaemoglobin in the blood and the treatment with methyline blue is warranted for high levels of maethemoglobin. If the patient has got a comorbid condition which impaired oxygen saturation, even with low levels of methaemoglobin, patient may become symptomatic and may warrant treatment [5]. When the methaemoglobin levels below 3\%, there are usually no symptoms. Cyanosis starts when it increases to $15 \%$. Dyspnoea usually sets in between the $30 \%-50 \%$. When severe patients can develop metabolic acidosis, cardiac arrhythmia, seizures, central nervous system depression and coma. Death usually occur with levels about $70 \%[6]$.

${ }^{1}$ University Medical Unit, Teaching Hospital, Jaffna, ${ }^{2}$ Department of Medicine, Faculty of Medicine, University of Jaffna, Sri Lanka.

Correspondence: KGAK, e-mail: <ajithkumarakg@gmail.com>. Received 21 August and revised version accepted 13 October 2012. Competing interests: none declared. 
Acquired maethaemoglobinaemia due to beef allergy or a toxin is also a possibility in this patient as it is much more common than the congenital form. However persistently low $\mathrm{O}_{2}$ saturation during the follow up period together with affected family members make congenital maethaemoglobinaemia the most likely diagnosis.

\section{References}

1. Ashurst J, Wasson M. Methaemoglobinemia: a systemic review of the pathophysiology, detection and treatment. Delaware Medical Journal 2011; 83: 203-8.

2. Lorenzo FR 5th, Phillips JD, Nussenzveig R, et al. Molecular basis of two novel mutations found in type I methaemo- globinemia. Blood Cells, Molecules, and Diseases 2011; 46: $277-81$.

3. Hamirani YS, Franklin W, Grifka RG, Stainback RF. Methaemoglobinemia in a young man. Texas Heart Institute Journal 2008; 35; 76-7.

4. Akhtar J, Johnston BD, Kranzelok EP. Mind the gap. Journal of Emergency Medicine 2007; 33: 131-2.

5. Skold A, Cosco DL, Klein R. Methaemoglobinemia: pathogenesis, diagnosis, and treatment. Southern Medical Journal 2011; 104: 757-61.

6. Nabukeera-Barungi N, Edison Mworozi E. Sudden onset methaemoglobinemia in a previously well child: a case report and literature review. The Pan African Medical Journal 2012; 11: 49. 